\title{
Combining selective extraction and easy stripping of lithium using a ternary synergistic solvent extraction system through regulation of $\mathrm{Fe}^{3+}$ coordination
}

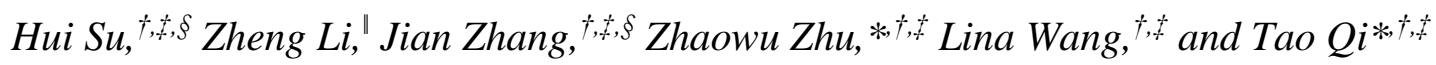

${ }^{\dagger}$ National Engineering Laboratory for Hydrometallurgical Cleaner Production Technology,

Beijing 100190, China

${ }^{\dagger}$ Key Laboratory of Green Process and Engineering, Institute of Process Engineering, Chinese Academy of Sciences, Beijing 100190, China

${ }^{\S}$ College of Chemistry and Chemical Engineering, University of Chinese Academy of Sciences, Beijing 101408, China

'Department of Chemistry, KU Leuven, Celestijnenlaan 200 F, B-3001 Heverlee, Belgium

\section{Corresponding author}

*Zhaowu Zhu. E-mail: zhwzhu@ @ipe.ac.cn, phone: +86 13311581061.

*Tao Qi. E-mail: tqi@ipe.ac.cn, phone:+86 13911132448. 
KEYWORDS: ternary solvent extraction, lithium, TBP, P507, stripping

ABSTRACT: Lithium is becoming increasingly important due to its essential role in lithium-ion batteries. Over $70 \%$ of the global lithium resources are found in salt lake brines, where lithium is always accompanied by magnesium. The system of TBP (tributyl phosphate) $/ \mathrm{FeCl}_{3}$ has been widely studied for selective lithium extraction from high Mg-containing salt lake brines. However, the system requires a high concentration of $\mathrm{HCl}$ for lithium stripping, which causes equipment corrosion, consumes large amounts of reagents and requires careful neutralization of the organic phase for regeneration. In this study, we develop a novel ternary synergistic solvent extraction system of $\mathrm{TBP} / \mathrm{FeCl}_{3} / \mathrm{P} 507$ ( $\mathrm{P} 507$ is 2-ethylhexyl phosphonic acid mono 2-ethylhexyl) to significantly enhance the stripping of lithium while largely maintaining lithium extraction capacity. During lithium extraction from $\mathrm{Mg}$-containing solutions, TBP and $\mathrm{FeCl}_{3}$ coordinate with lithium in the form of $\mathrm{Li} \cdot 2 \mathrm{TBP} \cdot \mathrm{FeCl}_{4}$, while $\mathrm{P} 507$ is not involved in the coordination. When the loaded organic phase is contacted with water, P507 and TBP synergistically coordinate with $\mathrm{Fe}^{3+}$ in the form of $\mathrm{FeCl}_{2} \mathrm{~L} \cdot(\mathrm{HL}) \cdot 2 \mathrm{TBP}$ (HL denotes P507), leading to efficient stripping of lithium due to the broken of the coordination structure of $\mathrm{Li} \cdot 2 \mathrm{TBP} \cdot \mathrm{FeCl}_{4}$, and $\mathrm{Fe}^{3+}$ is maintained in the organic phase for the next extraction cycle. The efficient stripping of lithium using only water, instead of high concentration $\mathrm{HCl}$, is a key step forward towards the sustainable extraction of lithium from brines. 


\section{INTRODUCTION}

Driven by the increasing popularity of electric vehicles, the consumption of lithium has been sharply increasing in the past 10 years, and the trend is expected to continue in the following 2-3 decades. ${ }^{1-4}$ Salt lake brines and pegmatites are the two main sources of lithium with the former accounting for over $70 \%$ of the total resources. ${ }^{5-6}$ Currently, the majority of the global lithium production is obtained from salt lake brines. ${ }^{1,7} \mathrm{The} \mathrm{Mg} / \mathrm{Li}$ ratios of salt lake brines in China are especially high, which makes lithium recovery more difficult. ${ }^{8}$

Solvent extraction (SX) is a promising technique for lithium extraction from $\mathrm{Mg}$-containing brines. In the 1960s, Nelli and Arthur found that $\mathrm{FeCl}_{3}$ and certain oxygen-containing extractants, particularly diisobutyl ketone (DIBK) and TBP, could selectively extract $\mathrm{Li}^{+}$over $\mathrm{Mg}^{2+}$ in chloride media. ${ }^{9}$ Afterward, the synergistic SX system of $\mathrm{TBP} / \mathrm{FeCl}_{3}$ attracted extensive studies for $\mathrm{Li}^{+}$and $\mathrm{Mg}^{2+}$ separations due to the good separation factor ( $\mathrm{SF}>300$ ), low cost and large scale availability of TBP. ${ }^{8,10-13}$ However, this extraction system has the problem of difficult stripping. Zhou et al. determined the complex structure of $\mathrm{Li}^{+}$extraction by TBP to be $\left[\mathrm{Li} \cdot(\mathrm{TBP}){ }_{x}\left(\mathrm{H}_{2} \mathrm{O}\right)_{4-x}\right]^{+}\left[\mathrm{FeCl}_{4}\right]^{-}(x=1,2) .{ }^{14}$ In some other studies, $x=2$ is often observed. ${ }^{15-16} \mathrm{In}$ this extraction, $\mathrm{Li}^{+}$forms a cationic complex with $\mathrm{TBP}$ and water, $\left[\mathrm{FeCl}_{4}\right]^{-}$works as the counter anion. The most commonly used stripping agent is $\mathrm{HCl}$, and the mechanism is replacing $\mathrm{Li}^{+}$by the $\mathrm{H}^{+}$in the complex. ${ }^{8,17}$ The extraction and stripping of $\mathrm{Li}^{+}$can be expressed by the following equations:

$$
\mathrm{Li}_{(a q)}^{+}+\mathrm{FeCl}_{4(\text { (aq) }}^{-}+2 \mathrm{TBP}_{(\text {org })} \rightleftarrows \mathrm{LiFeCl}_{4} \cdot 2 \mathrm{TBP}_{(\text {org })}
$$




$$
\mathrm{H}_{(\text {aq })}^{+}+\mathrm{LiFeCl}_{4} \cdot 2 \mathrm{TBP}_{(\text {org })} \rightleftarrows \mathrm{Li}_{(a q)}^{+}+\mathrm{HFeCl}_{4} \cdot 2 \mathrm{TBP} P_{(\text {org })}
$$

where the subscripts $a q$ and org stand for the aqueous and organic phase, respectively, and $x$ is assumed to be 2 . High concentration of $\mathrm{HCl}$ (up to $6 \mathrm{M}$ ) is required for stripping, because in addition to exchange with $\mathrm{Li}^{+}$, it is also extracted by TBP in a large amount, and TBP is used excessively in lithium extraction. ${ }^{18}$ The high $\mathrm{HCl}$ concentration not only corrodes equipment, but also requires careful neutralization of the organic phase to regenerate TBP for next recycling. Therefore, the difficult stripping has been the main obstacle, preventing the $\mathrm{TBP} / \mathrm{FeCl}_{3} \mathrm{SX}$ system from industrial applications for lithium extraction from brines.

Besides $\left[\mathrm{FeCl}_{4}\right]^{-},\left[\mathrm{PF}_{6}\right]^{-}$-containing ionic liquids (ILs) with hydrophilic cations also showed potential to extract $\mathrm{Li}^{+}$. In such extraction, the cations of the ionic liquids enter into the aqueous solution and the anions are involved in the complex formation with $\mathrm{Li}^{+}{ }^{19-20}$ Following this discovery, many kinds of ionic liquids ${ }^{21-22}$ and salts (e.g. $\mathrm{NaClO}_{4}$ and $\left.\mathrm{NaB}(\mathrm{Phen})_{4}\right)$ with symmetric anions were found to be similar in extraction capability of lithium with TBP. However, these ionic liquids have considerable limitations: expensive and lose cations (not reusable). Moreover, replacing $\mathrm{FeCl}_{3}$ with these alternative anions (either as salts or ionic liquids) does not really improve stripping, especially when a high organic to aqueous phase ratio (O/A) is used. These studies show that ionic liquids are now unsuitable for lithium recovery from brines.

In this study, we developed a novel ternary synergistic solvent extraction system of $\mathrm{TBP} / \mathrm{FeCl}_{3} / \mathrm{P} 507$ to enhance stripping of lithium using only water by controlling the coordination 
of $\mathrm{Fe}^{3+}$ during extraction and stripping, while largely maintaining the lithium extraction capacity. The mechanism of the lithium extraction and stripping of this system was explained and the structures of extracted complexes were proposed. It is proved to be a sustainable lithium extraction process with large-scale industrial application value.

\section{EXPERIMENTAL SECTION}

Reagents and Solution Preparation. $\mathrm{LiCl}(>97 \%), \mathrm{MgCl}_{2}(>99 \%), \mathrm{FeCl}_{3}(>98 \%)$ and $\mathrm{HCl}(37$ wt $\%$ ) were purchased from Beijing Chemical Works. The synthetic brine solutions were prepared by dissolving certain amounts of chloride salts into de-ionized water, according to the composition of real brine solutions. TBP (> 98.5\%) and P507 (> 95\%) was provided by Shanghai Rare Earth Chemical Co., Ltd. Sulfonated kerosene (MW=142-254) and cyclohexane (> 99.5\%) were purchased from Sinopharm Group Chemical Reagent Co. Organic solutions were prepared by mixing TBP and P507 with kerosene according to the required volume ratio. $\mathrm{AgNO}_{3}(>99.7 \%)$, $\mathrm{K}_{2} \mathrm{CrO}_{4}(>99.5 \%)$ and $\mathrm{NaOH}(>98 \%)$ used for $\mathrm{Cl}^{-}$concentration determination were purchased from Beijing reagents company.

Extraction Procedures. The synthetic feed solution containing $0.10 \mathrm{M} \mathrm{LiCl}, 0.13 \mathrm{M} \mathrm{FeCl}_{3}, 4.0$ $\mathrm{M} \mathrm{MgCl}_{2}$ and $0.03 \mathrm{M} \mathrm{HCl}$ were used to closely simulate the composition of concentrated brines in West Tajinar Salt Lake (China). The optimum Fe/Li ratio of 1.3/1 was selected based on our previous studies, and $0.03 \mathrm{M} \mathrm{HCl}$ was added to the solution to prevent the hydrolysis of $\mathrm{Fe}^{3+}$. The organic phase contained varying concentrations of TBP and P507 diluted in kerosene. The 
synthetic feed solution was mixed with the organic phase in hexagonal jars using a mechanic shaker (HD-100B, Jintan Yineng, China) with a O/A ratio of 1:1 $(20 \mathrm{~mL} / 20 \mathrm{~mL})$ at $25 \pm 2{ }^{\circ} \mathrm{C}$ for $30 \mathrm{~min}$. After shaking, the mixtures were settled for $30 \mathrm{~min}$ for phase separation. Subsequently, aqueous samples were taken from the bottom phases using a syringe with a long needle for the determinations of metal concentrations and $\mathrm{pH}$. The concentration of $\mathrm{Li}^{+}$and $\mathrm{Mg}^{2+}$ in the organic phases were determined after stripping with $6 \mathrm{M} \mathrm{HCl}$ and $\mathrm{Fe}^{3+}$ in the organic phases were calculated by mass balance based on aqueous concentration (because $\mathrm{Fe}^{3+}$ cannot be stripped by high $\mathrm{HCl}$ concentration solution).

The extraction percentage $E \%$, stripping percentage $S \%$, distribution ratio $D$ and separation factor $\alpha$ are defined as:

$$
\begin{gathered}
E \%=\frac{C_{\text {org }} \cdot V_{\text {org }}}{C_{\text {org }} \cdot V_{\text {org }}+C_{a q} \cdot V_{a q}} \times 100 \% \\
S \%=\frac{C_{\text {org }}-C_{\text {org }, s}}{C_{\text {org }}} \times 100 \% \\
D=\frac{C_{\text {org }}}{C_{a q}} \\
\alpha=\frac{D_{A}}{D_{B}}
\end{gathered}
$$

where $C_{o r g}$ and $C_{a q}, V_{o r g}$ and $V_{a q}$ are concentrations and volumes of the organic and the aqueous phase at extraction equilibrium, respectively; $C_{\text {org, } s}$ is the concentration of the organic phase after stripping; $D_{A}$ and $D_{B}$ are the distribution ratios of metals A and B, respectively. 
Determination of $\mathrm{Cl}^{-}$Concentration. The $\mathrm{Cl}^{-}$concentration was determined by $\mathrm{AgNO}_{3}$ titration using $\mathrm{K}_{2} \mathrm{CrO}_{4}$ as the indicator. The aqueous samples were diluted to the $\mathrm{Cl}^{-}$concentration range of $10-500 \mathrm{mg} \cdot \mathrm{L}^{-1}$. NaOH solution was added to the sample to adjust the $\mathrm{pH}$ to $6.5-10.5$, then $0.02 \mathrm{M} \mathrm{AgNO}_{3}$ standard solution was used for titration with $\mathrm{K}_{2} \mathrm{CrO}_{4}$ as the indicator. $\mathrm{Cl}^{-}$ concentration was calculated based on the consumption of $\mathrm{AgNO}_{3}$.

UV-Vis Spectrometry and Raman Spectrometry. UV-Vis spectra was acquired by characterizing the loaded organic samples, which were prepared by 60 vol $\%$ TBP-20 vol $\%$ P507-20 vol\% kerosene with the synthetic feed solution containing $0.1 \mathrm{M} \mathrm{LiCl}, 0.13 \mathrm{M} \mathrm{FeCl}_{3}$ and $0.03 \mathrm{M} \mathrm{HCl}$ under various $\mathrm{MgCl}_{2}$ concentrations. Raman spectra was acquired by characterizing the loaded organic samples which were prepared by 60 vol $\%$ TBP- 20 vol\% P507-20 vol\% cyclohexane with the above synthetic feed solution and subsequently, cyclohexane being evaporated.

Analysis. The concentrations of $\mathrm{Li}^{+}, \mathrm{Mg}^{2+}$ and $\mathrm{Fe}^{3+}$ in the aqueous samples were determined by inductively coupled plasma-optical emission spectroscopy (ICP-OES, Optima 5300V, Pekin-Elmer, USA) after diluting to a proper concentration range. A composite $\mathrm{pH}$ probe (Ross Sure-Flow 8172BN, Orion, US) connected with a pH meter (PHSJ-6L, INESA, Shanghai, China) was used to monitor the $\mathrm{pH}$ of aqueous samples. UV-Vis spectra were recorded on a UV-Visible spectrophotometer (9100b, Labtech, Beijing) using a pair of quartz cuvettes with $10.0 \mathrm{~mm}$ light path. The absorbance range is $0-3 \mathrm{ABS}$, resolution is $0.1 \mathrm{~nm}$, sweeping step length is $0.5 \mathrm{~nm}$, and the wavelength range is $50-1000 \mathrm{~nm}$. Raman spectra were recorded by a laser Raman 
spectrometer (LabRAM HR800, Horiba Jobin Yvon, France) with a Leica optical microscope to focus the laser light. The excitation light was the $514.5 \mathrm{~nm}$ line of an $\mathrm{Ar}^{+}$laser with a real output power of $10-50 \mathrm{~mW}$. The resolution is $0.3 \mathrm{~cm}^{-1}$ and the measurement range is $50-1000 \mathrm{~cm}^{-1}$.

\section{RESULTS AND DISCUSSION}

\subsection{Stripping of Lithium from the $\mathrm{TBP} / \mathrm{FeCl}_{3}$ System.}

Despite the fact that the extraction and stripping of lithium by the $\mathrm{TBP} / \mathrm{FeCl}_{3}$ system has been reported by many researchers, we tested the system again for comparison with the ternary system of $\mathrm{TBP} / \mathrm{FeCl}_{3} / \mathrm{P} 507$ in the following section. $60 \mathrm{vol} \% \mathrm{TBP}$ dissolved in kerosene was used for lithium extraction from the synthetic brine solution, because the third phase occurred when TBP concentration was lower than $60 \mathrm{vol} \%$. After extraction, $0.44 \mathrm{~g} \cdot \mathrm{L}^{-1} \mathrm{Li}^{+}, 1.9 \mathrm{~g} \cdot \mathrm{L}^{-1} \mathrm{Mg}^{2+}$ and 5.85 $\mathrm{g} \cdot \mathrm{L}^{-1} \mathrm{Fe}^{3+}$ was loaded to the organic phase, and the extraction of $\mathrm{Li}^{+}, \mathrm{Mg}^{2+}$ and $\mathrm{Fe}^{3+}$ were $72 \%$, $1.9 \%$ and $100 \%$, respectively. The loaded organic phase was then stripped by $\mathrm{HCl}$ and water with various phase ratios. The effect of $\mathrm{HCl}$ concentration for the stripping of metals with a $\mathrm{O} / \mathrm{A}$ ratio of 1 is shown in Figure 1a. Almost all metal ions were stripped by water, including $\mathrm{Fe}^{3+}$. The stripping of $\mathrm{Fe}^{3+}$ is due to the lack of chloride anions, which is essential for the formation of $\left[\mathrm{FeCl}_{4}\right]^{-}$. Once $\left[\mathrm{FeCl}_{4}\right]^{-}$cannot be maintained, $\mathrm{Fe}^{3+}$ is subjucted to the aqueous solution and consequently $\mathrm{Li}^{+}$is stripped as well due to the broken of the $\mathrm{Li} \cdot 2 \mathrm{TBP} \cdot \mathrm{FeCl}_{4}$, according to Eq. (1).

With the increase of $\mathrm{HCl}$ concentration, the stripping percentage of $\mathrm{Fe}^{3+}$ decreased rapidly and only $5 \% \mathrm{Fe}^{3+}$ was stripped at $3.0 \mathrm{M} \mathrm{HCl}$, while stripping of $\mathrm{Li}^{+}$and $\mathrm{Mg}^{2+}$ were still almost 
complete. Under this condition, $\mathrm{Li}^{+}$was stripped by being replaced by $\mathrm{H}^{+}$, while $\mathrm{Fe}^{3+}$ was kept in the organic phase in the form of $\mathrm{H} \cdot 2 \mathrm{TBP} \cdot \mathrm{FeCl}_{4}$, according to Eq. (2). Despite almost complete stripping of $\mathrm{Li}^{+}$, the concentration of $\mathrm{Li}^{+}$in the stripping solution was only $0.44 \mathrm{~g} \cdot \mathrm{L}^{-1}$ at $3.0 \mathrm{M}$ $\mathrm{HCl}$, which is too low for the further precipitation of $\mathrm{Li}_{2} \mathrm{CO}_{3}$.

In order to concentrate $\mathrm{Li}^{+}$in the stripping solution, the effect of $\mathrm{O} / \mathrm{A}$ ratios on lithium stripping was investigated with $3.0 \mathrm{M} \mathrm{HCl}$ (Figure 1b). In all phase ratios, $\mathrm{Fe}^{3+}$ was largely maintained in the organic phase. When $\mathrm{O} / \mathrm{A}$ ratio was less than 10 , more than $95 \% \mathrm{Li}^{+}$was stripped. The concentration of $\mathrm{Li}^{+}$in the aqueous phase was $4.37 \mathrm{~g} / \mathrm{L}$ at the $\mathrm{O} / \mathrm{A}$ ratio of 10 . When $\mathrm{O} / \mathrm{A}$ ratio was further increased, the stripping of $\mathrm{Li}^{+}$decreased rapidly and it became $63 \%$, $30 \%$ and $4 \%$ at the $\mathrm{O} / \mathrm{A}$ ratio of 20,30 and 50 , respectively.

The effect of O/A ratios on the stripping using water was also studied, with results shown in Figure 1c. With the increase of the $\mathrm{O} / \mathrm{A}$ ratio, the stripping of $\mathrm{Li}^{+}$and $\mathrm{Fe}^{3+}$ decreased rapidly and they could hardly be stripped at the O/A ratio of 30 . The stripping of $\mathrm{Li}^{+}$and $\mathrm{Fe}^{3+}$ has the same trend, meaning that either both $\mathrm{Li}^{+}$and $\mathrm{Fe}^{3+}$ are kept in the organic phase with very low stripping, or $\mathrm{Li}^{+}$is stripped but $\mathrm{Fe}^{3+}$ is lost to the aqueous solution as well. Neither of the two cases is wanted. Therefore, water cannot strip $\mathrm{Li}^{+}$from the $\mathrm{TBP} / \mathrm{FeCl}_{3}$ system. 

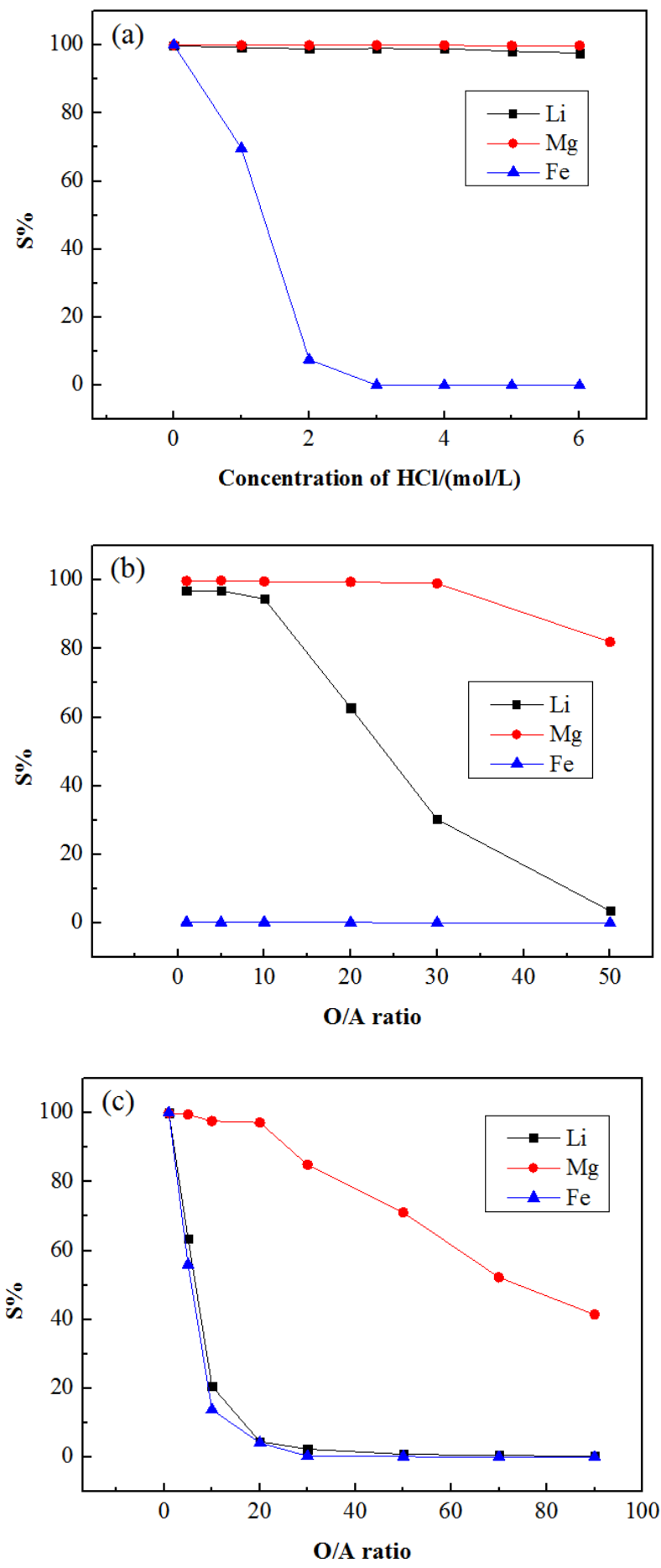

Figure 1. Stripping of lithium from the loaded organic phase of the $\mathrm{TBP} / \mathrm{FeCl}_{3}$ system: (a). effect of $\mathrm{HCl}$ concentration with a $\mathrm{O} / \mathrm{A}$ ratio of 1 , (b). effect of $\mathrm{O} / \mathrm{A}$ ratio using $3.0 \mathrm{M} \mathrm{HCl}$ as the stripping agent, (c). effect of $\mathrm{O} / \mathrm{A}$ ratio using water as the stripping agent. 


\subsection{Stripping of Lithium from the New TBP/FeCl3/P507 System.}

Following the performance of the well-known $\mathrm{TBP} / \mathrm{FeCl}_{3}$ system, we tested the new $\mathrm{TBP} / \mathrm{FeCl}_{3} / \mathrm{P} 507$ system for $\mathrm{Li}^{+}$extraction and stripping. Firstly, various volumes of P507 was added to the $\mathrm{TBP} / \mathrm{FeCl}_{3}$ system to test the extraction of metals. It was found that P507 slightly suppresses the extraction of $\mathrm{Li}^{+}$, as the extraction of $\mathrm{Li}^{+}$slightly decreases with increasing P507 concentration (Figure 2). 20 vol\% P507 was chosen because under this condition $\mathrm{Li}^{+}$extracting capacity is largely maintained while P507 is high enough to play a role in the stripping. Therefore the new $\mathrm{TBP} / \mathrm{FeCl}_{3} / \mathrm{P} 507$ system has 60 vol\% TBP, 20 vol\% P507 in kerosene and $0.13 \mathrm{M} \mathrm{FeCl}_{3}$ (loaded from the aqueous solution). Then, the organic phase was contacted with the synthetic brine solution to load meatls. It was found that $5.84 \mathrm{~g} \cdot \mathrm{L}^{-1} \mathrm{Fe}^{3+}(100 \%), 0.35 \mathrm{~g} \cdot \mathrm{L}^{-1}$ $\mathrm{Li}^{+}(57 \%)$ and $2.68 \mathrm{~g} \cdot \mathrm{L}^{-1} \mathrm{Mg}^{2+}(2.7 \%)$ was extracted.

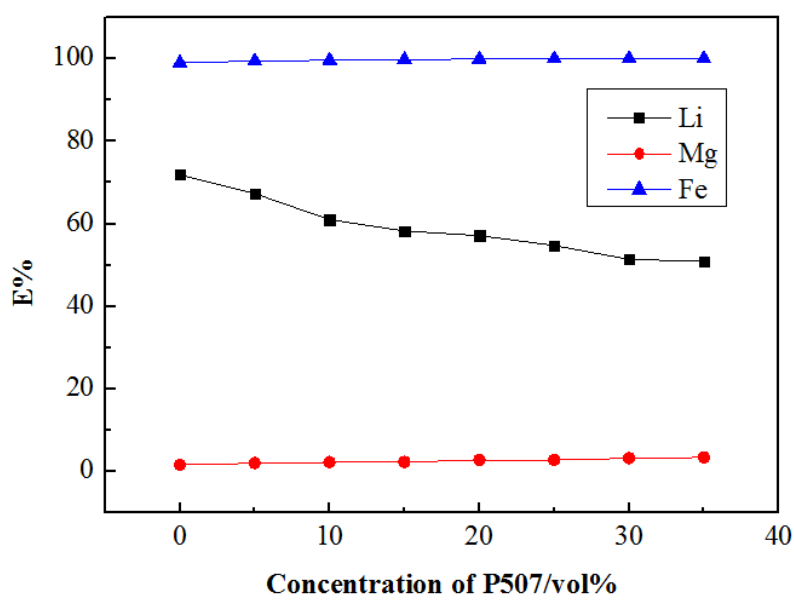

Figure 2. Effect of P507 concentration on metals extraction.

The loaded organic phase was stripped with water at different O/A ratios with the results 
shown in Figure 3a. By contrast to the $\mathrm{TBP} / \mathrm{FeCl}_{3}$ system where the stripping of $\mathrm{Li}^{+}$and $\mathrm{Fe}^{3+}$ have the same trend (Figure 1c), the stripping lines of $\mathrm{Li}^{+}$and $\mathrm{Fe}^{3+}$ are separated in the new $\mathrm{TBP} / \mathrm{FeCl}_{3} / \mathrm{P} 507$ system when the $\mathrm{O} / \mathrm{A}$ ratio was less than 20 , meaning that $\mathrm{Li}^{+}$can be stripped while maintaining $\mathrm{Fe}^{3+}$ in the organic phase, which is a preferred result. However, with the further increase of $\mathrm{O} / \mathrm{A}$ ratio, stripping of lithium decreased rapidly. The reduction of $\mathrm{Li}^{+}$ stripping was due to the increase of $\mathrm{Cl}^{-}$concentration that is mainly caused by the increase of $\mathrm{MgCl}_{2}$ concentration in the aqueous phase. Although the percentage extraction of $\mathrm{MgCl}_{2}$ is low (about 2\%), the amount is large because $\mathrm{MgCl}_{2}$ in the feed solution is high. In order to obtain high $\mathrm{Li}^{+}$stripping and concentrate $\mathrm{Li}^{+}$in the stripping solution at a large $\mathrm{O} / \mathrm{A}$ ratio, $\mathrm{MgCl}_{2}$ should be scrubbed before lithium stripping. According to Figure $3 \mathrm{a}$, at the $\mathrm{O} / \mathrm{A}$ ratio of $20, \mathrm{Li}^{+}$and $\mathrm{Fe}^{3+}$ were hardly scrubbed (or stripped) $\left(5.2 \%\right.$ and $<0.01 \%$, respectively), while about $75 \% \mathrm{Mg}^{2+}$ was scrubbed. The $\mathrm{Mg}^{2+}$ and $\mathrm{Li}^{+}$concentration in the aqueous phase after scrubbing was $>70$ $\mathrm{g} \cdot \mathrm{L}^{-1}$ and $<0.7 \mathrm{~g} \cdot \mathrm{L}^{-1}$. This aqueous solution can be sent back to the feed solution for further recovery of the scrubbed $\mathrm{Li}^{+}$without changing the composition of the feed solution much. The scrubbed organic phase can be further stripped by water.

The scrubbed organic phase was then further stripped with water at different O/A ratios (Figure 3b). Compared with Figure 1c, the $\mathrm{TBP} / \mathrm{FeCl}_{3} / \mathrm{P} 507$ system exhibited dramatically different trends for $\mathrm{Li}^{+}$and $\mathrm{Fe}^{3+}$ stripping. The stripping of $\mathrm{Li}^{+}$was close to $100 \%$, and that of $\mathrm{Fe}^{3+}$ was only about $16 \%$ at $\mathrm{O} / \mathrm{A}$ ratio of 1 . With the increasing $\mathrm{O} / \mathrm{A}$ ratio, the loss of $\mathrm{Fe}^{3+}$ to the aqueous solution minimized rapidly, and the stripping of $\mathrm{Li}^{+}$decreased from the $\mathrm{O} / \mathrm{A}$ ratio of 20 
onwards. The detail results for O/A ratio of 20 and 30 are listed in Table 1. At the O/A ratio of $20, \mathrm{Li}^{+}$was completely stripped, the resultant stripping solution had $6.70 \mathrm{~g} / \mathrm{L} \mathrm{of} \mathrm{Li}^{+}, 0.90 \mathrm{~g} \cdot \mathrm{L}^{-1}$ $\mathrm{Fe}^{3+}\left(0.68 \%\right.$ stripping) and $7.14 \mathrm{~g} \cdot \mathrm{L}^{-1} \mathrm{Mg}^{2+}$ (91\% stripping). At the $\mathrm{O} / \mathrm{A}$ ratio of 30 , the stripping of $\mathrm{Li}^{+}$was about $85 \%$, and the concentration of $\mathrm{Li}^{+}$in the stripping solution reached a maximum of $8.25 \mathrm{~g} / \mathrm{L}$. Only $0.41 \mathrm{~g} \cdot \mathrm{L}^{-1} \mathrm{Fe}^{3+}$ was stripped to the aqueous solution, which is largely negligible. However, the concentration of $\mathrm{Mg}^{2+}$ in the stripping solution reached $9.16 \mathrm{~g} \cdot \mathrm{L}^{-1} \cdot \mathrm{Mg}^{2+}$ can be minimized by optimizing the scrubbing stages, which will be discussed in our next study. In summary, in the new $\mathrm{TBP} / \mathrm{FeCl}_{3} / \mathrm{P} 507$ system, $\mathrm{Mg}^{2+}$ can be largely scrubbed by water at the $\mathrm{O} / \mathrm{A}$ ratio of 20 with only $5 \%$ scrubbing of $\mathrm{Li}^{+}$and no loss of $\mathrm{Fe}^{3+}$; then $\mathrm{Li}^{+}$in the scrubbed organic phase can be efficiently stripped by water at the O/A ratio of 20 with little loss of $\mathrm{Fe}^{3+}$. The stripped organic phase is readily reusable in the next extraction cycle without regeneration.
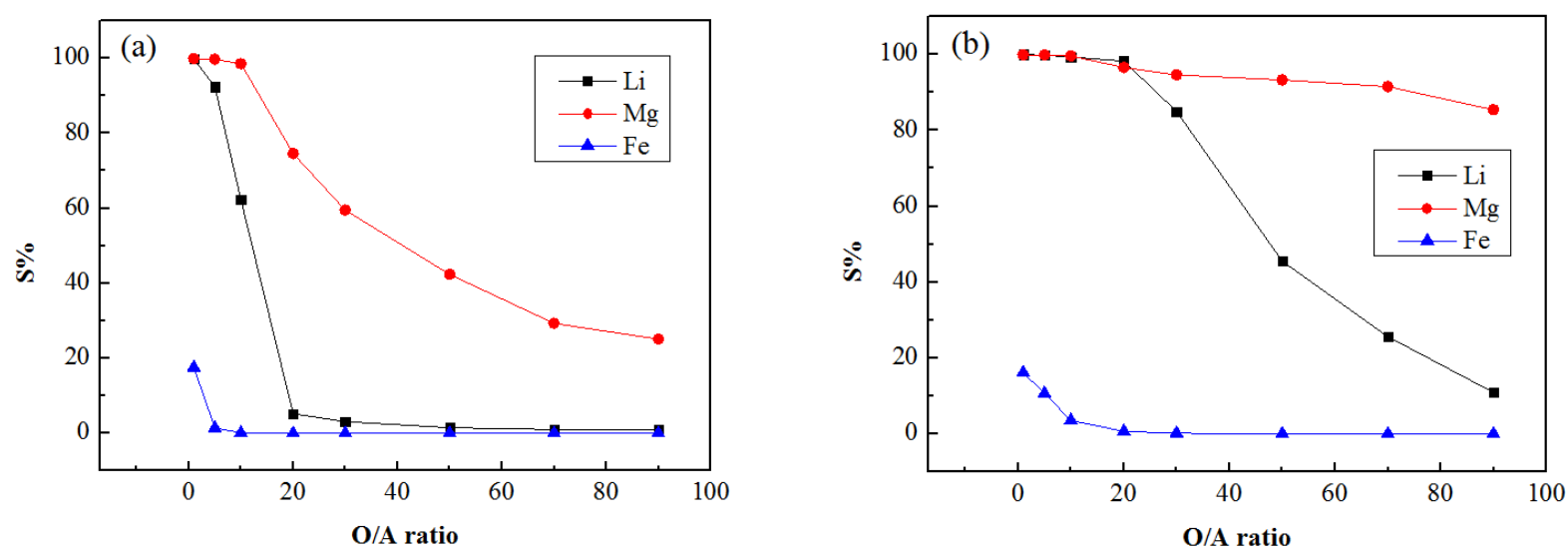

Figure 3. Stripping (scrubbing) of $\mathrm{Li}^{+}$from the loaded organic phase by water in the $\mathrm{TBP} / \mathrm{FeCl}_{3} / \mathrm{P} 507$ system:

(a) scrubbing of $\mathrm{Mg}^{2+}$ by water; (b) stripping of $\mathrm{Li}^{+}$by water.

Table 1. Metals stripping and concentrations in stripping solution at the O/A ratios of 20 and 30 in 
$\mathrm{TBP} / \mathrm{FeCl}_{3} / \mathrm{P} 507$ system

\begin{tabular}{ccccc}
\hline & O/A ratio & $\mathrm{Li}^{+}$ & $\mathrm{Fe}^{3+}$ & $\mathrm{Mg}^{2+}$ \\
\hline Stripping/\% & 20 & 100 & 0.68 & 91 \\
& 30 & 85 & 0.21 & 95 \\
\hline $\begin{array}{c}\text { Concentration } \\
\text { in stripping } \\
\text { solution } /\left(\mathrm{g} \cdot \mathrm{L}^{-1}\right)\end{array}$ & 20 & 6.70 & 0.90 & 7.14 \\
\hline
\end{tabular}

\subsection{Lithium Extraction and Stripping Mechanism from the TBP/FeCl$/ \mathrm{P}_{3}$ (07 System.}

\subsubsection{Extraction of $\mathrm{Fe}^{3+}$ by $\mathrm{P507}$ alone system.}

To investigate the extraction of metals by the ternary system of $\mathrm{TBP} / \mathrm{FeCl}_{3} / \mathrm{P} 507$, the extraction of metals by P507 alone system was firstly studied. The aqueous solutions containing lower concentrations $0.10 \mathrm{M} \mathrm{LiCl}, 0.10 \mathrm{M} \mathrm{FeCl}_{3}$ and $0.10 \mathrm{M} \mathrm{MgCl}_{2}$ were mixed with P507 diluted in kerosene to avoid the effect of solution ionic strength. The effect of P507 concentration on metals extraction has been investigated with the results shown in Figure 4. $\mathrm{Fe}^{3+}$ was efficiently extracted with the increase of P507 concentration, while $\mathrm{Li}^{+}$was slightly extracted, and the extraction of $\mathrm{Mg}^{2+}$ was also low, although higher than $\mathrm{Li}^{+}$. 


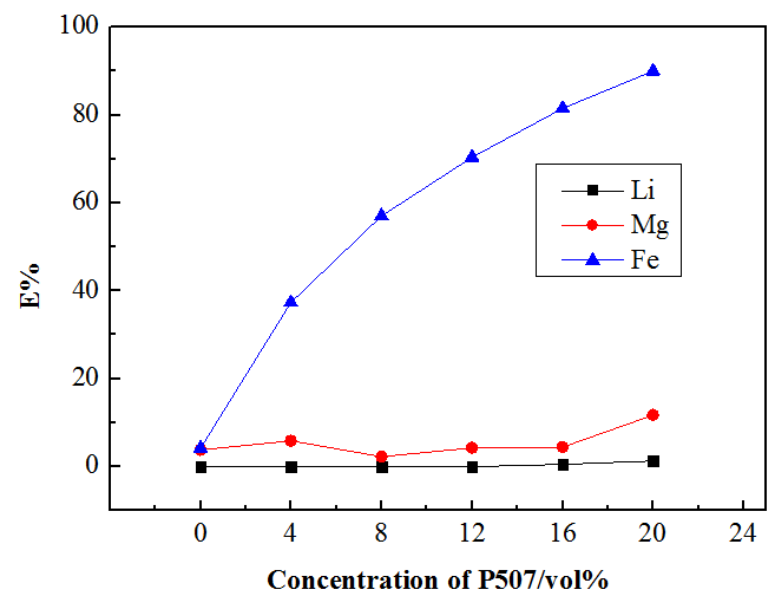

Figure 4. Effect of P507 concentration on metals extraction in P507 alone system.

The extraction of $\mathrm{Fe}^{3+}$ from the chloride solution with P507 alone can be described as Eq. (8). P507 is shown to be a dimer (HL) 2 in non-polar solvents like kerosene. ${ }^{23}$

$$
\mathrm{Fe}^{3+}{ }_{(a q)}+m \mathrm{Cl}_{(a q)}^{-}+\mathrm{n}(H L)_{2(\text { org })} \rightleftarrows \mathrm{FeCl}_{m} L_{3-m} \cdot(H L)_{2 n-3+m(\text { org })}+(3-m) H_{(a q)}^{+}
$$

where $m$ and $n$ are the stoichiometry of $\mathrm{Cl}^{-}$and (HL) 2 in the reaction, respectively. The equilibrium constant $\left(\mathrm{K}_{\mathrm{ex}}\right)$ of the extraction reaction is shown in Eq. (9):

$$
K_{e x}=\frac{\left[\mathrm{FeCl}_{m} L_{3-m} \cdot(\mathrm{HL})_{2 n-3+m}\right]_{(o r g)}\left[\mathrm{H}^{+}\right]_{(a q)}^{3-m}}{\left[\mathrm{Fe}^{3+}\right]_{(a q)}\left[\mathrm{Cl}^{-}\right]_{(a q)}^{m}\left[(H L)_{2}\right]_{(o r g)}^{n}}
$$

The distribution ratio of $\mathrm{Fe}^{3+}(\mathrm{D})$ is calculated as:

$$
D=\frac{\left[F e C l_{m} L_{3-m} \cdot(H L)_{2 n-3+m}\right]_{(o r g)}}{\left[F e^{3+}\right]_{(a q)}}
$$

Taking logarithm on both sides of the resulting equation by inserting Eq. (10) into Eq. (9) leads to: 


$$
\log D=\log K_{e x}-(3-m) \log \left[H^{+}\right]_{(a q)}+m \log \left[C l^{-}\right]_{(a q)}+n \log \left[(H L)_{2}\right]_{(o r g)}
$$

Since $\mathrm{LiCl}$ is not extracted by $\mathrm{P} 507$, it was chosen as a chloride source added to the $\mathrm{FeCl}_{3}$ solution to adjust the concentration of $\mathrm{Cl}^{-}$. Plotting the $\left(\log \mathrm{D}+\log \left[\mathrm{H}^{+}\right]\right)$against the $\log \left[\mathrm{Cl}^{-}\right]$, while maintaining the concentration of P507 constant, gives a straight line with a slope close to 2 (Figure 5a). This slope mean that $m=2$ in $\mathrm{Eq}(8)$, indicating that extraction of one mole $\mathrm{Fe}^{3+}$ requires two moles of $\mathrm{Cl}^{-}$, and one mole of $\mathrm{H}^{+}$is released. Biswas et al. studied the solvent extraction of $\mathrm{Fe}^{3+}$ from the chloride solution by di-(2-ethylhexyl) phosphoric acid (P204 HA) in kerosene, and also found that $\mathrm{FeCl}_{2}{ }^{+}$was extracted into the organic phase and one mole of $\mathrm{H}^{+}$ was released. The extracted species was proposed to be $\left[\mathrm{FeCl}_{2} \mathrm{~A} \cdot(\mathrm{HA})_{3}\right]$ at $1.0 \mathrm{M}$ aqueous $\mathrm{Cl}^{-}$ concentration. ${ }^{24}$ Since both P204 and P507 are phosphoruous-based acidic extractants and their structures and properties are very similar, the species of $\mathrm{Fe}^{3+}$ extraction by P204 and P507 are expected to be similar. ${ }^{25-26}$

Plotting the $\left(\log \mathrm{D}+\log \left[\mathrm{H}^{+}\right]\right)$against the $\log [\mathrm{P} 507]$, while maintaining the concentration of $\mathrm{Cl}^{-}$constant gives out a straight line with a slope close to 2 (Figure 5b). This slope means that $n$ $=2$ in Eq. (8), indicating that extraction of one mole $\mathrm{Fe}^{3+}$ requires two moles of dimer P507 $\left((\mathrm{HL})_{2}\right)$. 

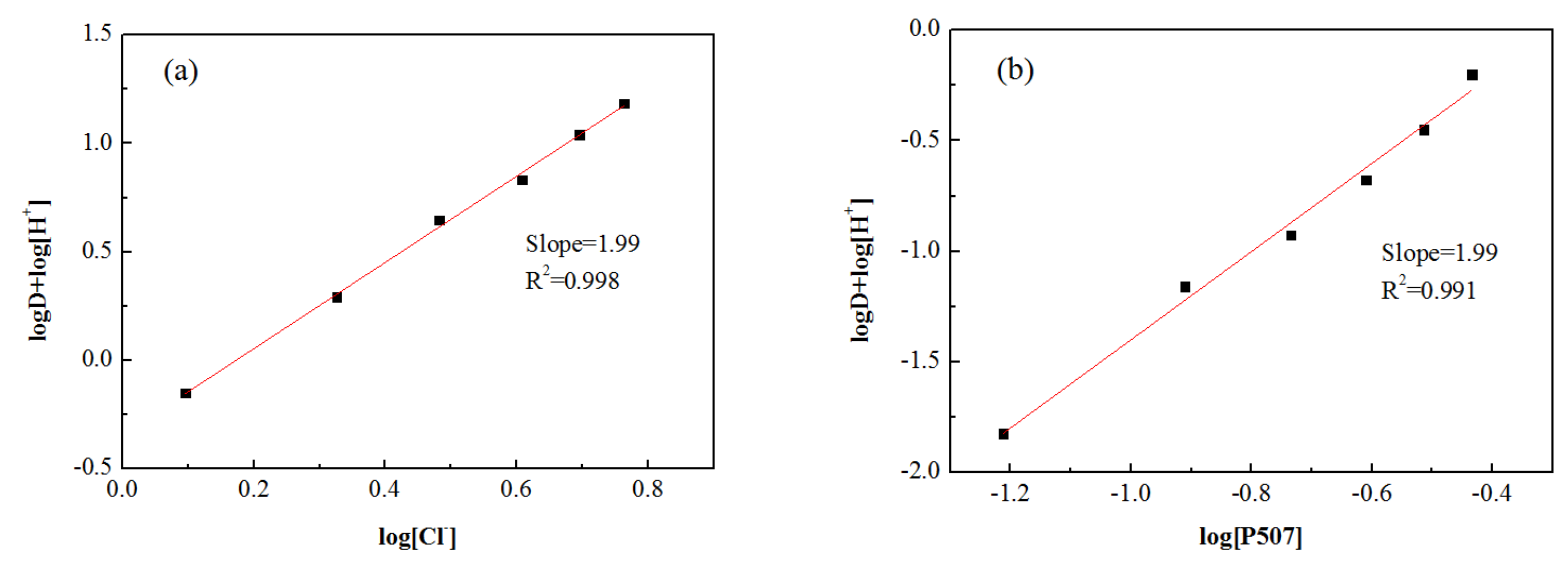

Figure 5. Effect of $\mathrm{Cl}^{-}$and $\mathrm{P} 507$ concentraction on the extraction of $\mathrm{Fe}^{3+} . \mathrm{FeCl}_{3}$ concentration was $0.1 \mathrm{M}$ in all cases. (a) 0.40 M P507; (b) $0.30 \mathrm{M}\left[\mathrm{Cl}^{-}\right]$.

$$
\mathrm{Fe}_{(a q)}^{3+}+2 \mathrm{Cl}_{(a q)}^{+}+2(H L)_{2(\text { org })} \rightleftarrows \mathrm{FeCl}_{2} L \cdot(H L)_{3(\text { org })}+{H^{+}}_{(a q)}
$$

On the basis of the above slope analysis and the principle of charge neutrality, the species of $\mathrm{Fe}^{3+}$ in the loaded organic phase is proposed to be $\mathrm{FeCl}_{2} \mathrm{~L} \cdot(\mathrm{HL})_{3}$, as expressed by Eq. (12). The structure of the complex is proposed as shown in Figure 6a, in which $\mathrm{Fe}^{3+}$ has a coordination number of six. The negatively charged $\mathrm{P}_{-} \mathrm{O}^{-}$group and the two $\mathrm{Cl}^{-}$anions should directly bind to $\mathrm{Fe}^{3+}$ for charge neutrality, and the three neutral $\mathrm{P} 507$ molecues bind to $\mathrm{Fe}^{3+}$ via the polar $\mathrm{P}=\mathrm{O}$ group. The coordination mechanism of this structure is the same as the extraction of $\mathrm{Fe}^{3+}$ by P204, as proposed by Jin et al. ${ }^{25}$ 
(a)

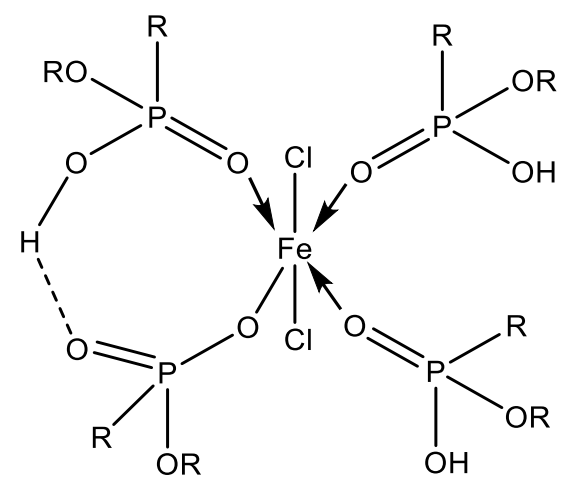

(b)

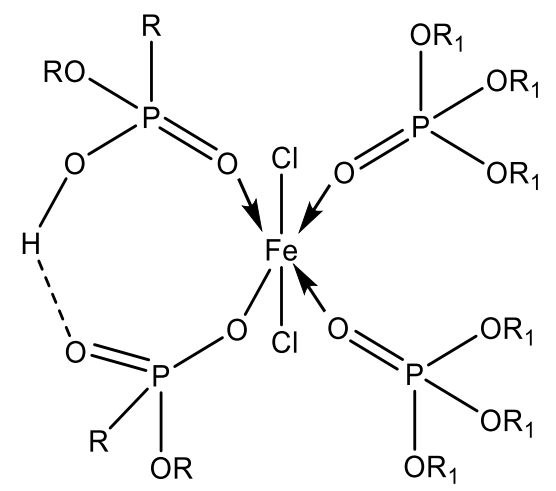

Figure 6. The possible structure of the complex (a) $\mathrm{FeCl}_{2} \mathrm{~L} \cdot(\mathrm{HL})_{3}$ and (b) $\mathrm{FeCl}_{2} \mathrm{~L} \cdot(\mathrm{HL}) \cdot 2 \mathrm{TBP} . \mathrm{R}=$ $-\mathrm{CH}_{2} \mathrm{CH}\left(\mathrm{C}_{2} \mathrm{H}_{5}\right) \mathrm{CH}_{2} \mathrm{CH}_{2} \mathrm{CH}_{2} \mathrm{CH}_{3} ; \mathrm{R}_{1}=-\mathrm{CH}_{2} \mathrm{CH}_{2} \mathrm{CH}_{2} \mathrm{CH}_{3}$.

\subsubsection{Extraction of $\mathrm{Fe}^{3+}$ by the $\mathrm{TBP} / \mathrm{FeCl}_{3} / \mathrm{P507}$ System.}

When $\mathrm{Fe}^{3+}$ was extracted by the TBP/P507 solvent mixture in chloride solution, the reaction can be described as Eq. (13).

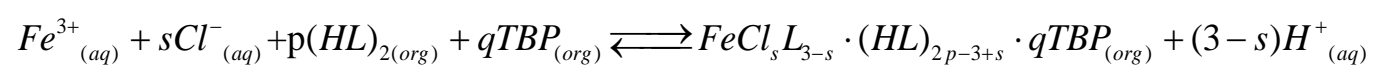

where $s, p$ and $q$ are the stoichiometry of $\mathrm{Cl}^{-},(\mathrm{HL})_{2}$ and TBP in the reaction, respectively. The equilibrium constant $\left(\mathrm{K}_{\mathrm{ex}}{ }^{\prime}\right)$ of the extraction reaction shown in Eq. (14) is:

$$
K_{e x}^{\prime}=\frac{\left[F e C l_{s} L_{3-s} \cdot(H L)_{2 p-3+s} \cdot q T B P\right]_{(o r g)}\left[H^{+}\right]_{(a q)}^{3-s}}{\left.\left[F^{3+}\right]_{(a q)}\left[C l^{-}\right]_{(a q)}^{s}\left[(H L)_{2}\right]_{(o r g}^{p}\right)}
$$

The distribution ratio of $\mathrm{Fe}^{3+}\left(\mathrm{D}^{\prime}\right)$ is calculated as:

$$
D^{\prime}=\frac{\left[F e C l_{s} L_{3-s} \cdot(H L)_{2 p-3+s} \cdot q T B P\right]_{(o r g)}}{\left[\mathrm{Fe}^{3+}\right]_{(a q)}}
$$


Taking logarithm on both sides of the resulting equation after inserting Eq. (15) into Eq. (14) leads to:

$$
\log D^{\prime}=\log K_{e x}{ }^{\prime}-(3-s) \log \left[H^{+}\right]_{(a q)}+s \log \left[C l^{-}\right]_{(a q)}+p \log \left[(H L)_{2}\right]_{(\text {org })}+q \log [T B P]_{(\text {org })}
$$

The concentration of $\mathrm{Cl}^{-}$in the solution was varied by adding $\mathrm{LiCl}$. Plotting the $\left(\log \mathrm{D}^{\prime}+\right.$ $\log \left[\mathrm{H}^{+}\right]$) against the $\log \left[\mathrm{Cl}^{-}\right]$, while maintaining the concentration of TBP and P507 constant, gives out a straight line with a slope close to 2 (Figure 7a). The slope means that $s=2$ indicating that extraction of one mole $\mathrm{Fe}^{3+}$ requires two moles of $\mathrm{Cl}^{-}$anions and and one mole of $\mathrm{H}^{+}$is released. Following the same procedure, slope analysis for P507 and TBP yields two slopes chlose to 1 and 2, respectively (Figures 7b, 7c). These slopes mean that $p=1$ and $q=2$. In other words, one P507 dimer and two TBP molecues are involved in the extraction of one moles of $\mathrm{Fe}^{3+}$. Now Eq. (16) can be expressed as Eq. (17). The extracted species is therefore proposed to be $\mathrm{FeCl}_{2} \mathrm{~L} \cdot(\mathrm{HL}) \cdot 2 \mathrm{TBP}$. The structure of the complex is shown in Figure 6b, by analogy to Figure 6a. In the TBP/P507 extraction system, two TBP molecues replaces one P507 dimer in the extracted complex, compared to the P507 alone system.
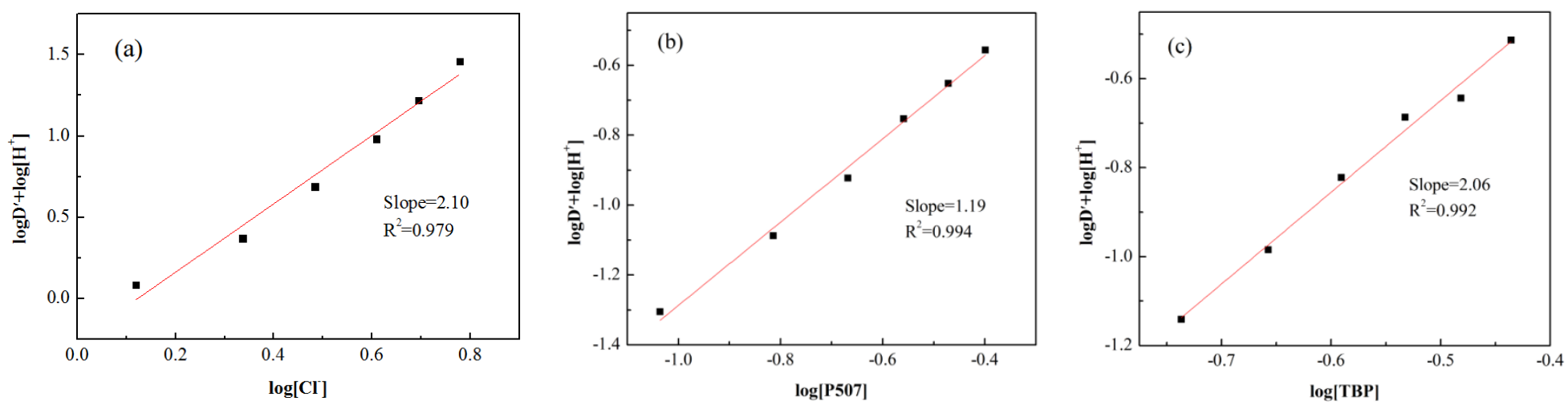
Figure 7. Effect of $\mathrm{Cl}^{-}, \mathrm{P} 507$ and TBP concentraction on the extraction of $\mathrm{Fe}^{3+}$. $\mathrm{FeCl}_{3}$ concentration was $0.1 \mathrm{M}$ in all cases. The organic phase was: (a) 0.15 M TBP and 0.15 M P507, (b) 0.15 M TBP and varying P507 cocnentrations, (c) 0.09 M P507 and varying TBP concentrations.

$$
\mathrm{Fe}_{(a q)}^{3+}+2 \mathrm{Cl}_{(a q)}^{+}+(H L)_{2(\text { org })}+2 \mathrm{TBP}_{(\text {org })} \rightleftarrows \mathrm{FeCl}_{2} L \cdot(\mathrm{HL}) \cdot 2 \mathrm{TBP} P_{(\text {org })}+H_{(a q)}^{+}
$$

\subsubsection{Effect of Chloride Concentration on $\mathrm{Fe}^{3+}$ Extraction by the $\mathrm{TBP} / \mathrm{FeCl}_{3} / \mathrm{P507}$ System.}

During the extraction of $\mathrm{Li}^{+}$from concentrated brine solutions, $\mathrm{Cl}^{-}$concentration is high up to 8 M. However, the $\mathrm{Cl}^{-}$concentration is low when stripping using water. Therefore, it is helpful to understand the role of $\mathrm{Cl}^{-}$concentration on the extraction and stripping of $\mathrm{Li}^{+}$. The loaded organic samples mixed with the synthetic feed solution under various $\mathrm{MgCl}_{2}$ concentrations have been characterized by UV-visible spectra and Raman spectra with results shown in Figure 8. When there was no $\mathrm{MgCl}_{2}$ in the aqueous solution, the UV-Vis spectrum (Figure 8a) does not shown characteristic bands. With the addition of $\mathrm{MgCl}_{2}$ three main absorption peaks appeared at $531 \mathrm{~nm}, 619 \mathrm{~nm}$ and $683 \mathrm{~nm}$ which well match the characteristic absorption peaks of $\mathrm{FeCl}_{4}{ }^{-14,27-29}$ suggesting that $\mathrm{Fe}^{3+}$ presented in the organic was in the form of $\mathrm{FeCl}_{4}^{-}$. $\mathrm{Raman}$ spectra (Figure 8b) of these organic samples showed distinct exhibiting bands at 111, 333 and $384 \mathrm{~cm}^{-1}$ at the concentration of $\mathrm{MgCl}_{2}$ greater than $0 \mathrm{M}$, which are also attributed to the vibrations of $\mathrm{FeCl}_{4}{ }^{-},{ }^{30-33}$ again suggesting existence of $\mathrm{FeCl}_{4}^{-}$. In addition, the intensity of both the UV-visible spectra and the Raman spectra increase with the increasing $\mathrm{MgCl}_{2}$ concentration, meaning that $\mathrm{Cl}^{-}$enhance the formation of $\mathrm{FeCl}_{4}{ }^{-}$. 
The metals extraction at different concentrations of $\mathrm{MgCl}_{2}$ is shown in Table 2. Without $\mathrm{MgCl}_{2}$, the extraction of $\mathrm{Li}^{+}$is negligible and the extraction of $\mathrm{Fe}^{3+}$ is about $78 \%$, which is assumed to be extracted by TBP and P507 in the form of $\mathrm{FeCl}_{2} \mathrm{~L} \cdot(\mathrm{HL}) \cdot 2 \mathrm{TBP}$. With the addition of $\mathrm{MgCl}_{2}$, the extraction of both $\mathrm{Li}^{+}$and $\mathrm{Fe}^{3+}$ increased. On the one hand, $\mathrm{Fe}^{3+}$ is still partially extracted as $\mathrm{FeCl}_{2} \mathrm{~L} \cdot(\mathrm{HL}) \cdot 2 \mathrm{TBP}$; on the other hand, more and more $\mathrm{Fe}^{3+}$ is extracted in the form of $\mathrm{Li} \cdot 2 \mathrm{TBP} \cdot \mathrm{FeCl}_{4}$, which is supported by the increasing intensity of the UV-Vis and Raman spectra of $\mathrm{FeCl}_{4}{ }^{-}$and the increasing extraction of $\mathrm{Li}^{+}$. At the highest $\mathrm{MgCl}_{2}$ concentration (4.0 $\left.\mathrm{mol} \cdot \mathrm{L}^{-}\right)$, the $\mathrm{Li} \cdot 2 \mathrm{TBP} \cdot \mathrm{FeCl}_{4}$ species should be dominating because of too high $\mathrm{Cl}^{-}$cocnentration, and P507 is hardly involved in $\mathrm{Fe}^{3+}$ extraction although it is presented in the organic phase. This condition is the same as the $\mathrm{Li}^{+}$extraction from the brine solution.
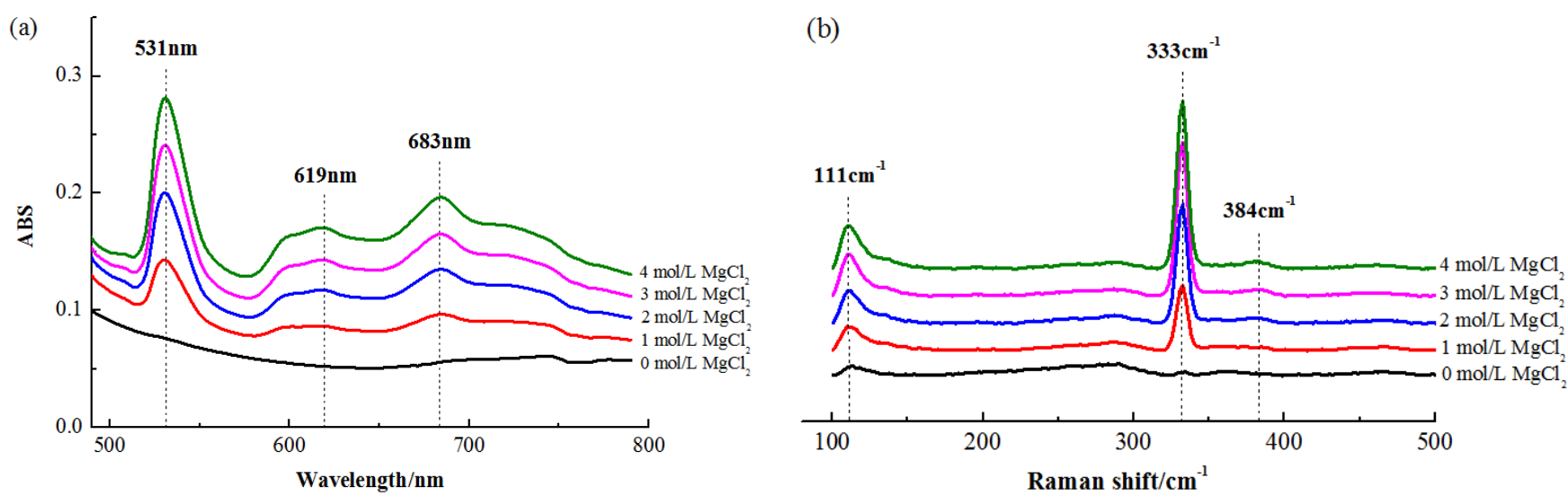

Figure 8. Spectral analysis of the loaded organic phase. (a) UV-Visible spectra; (b) Raman spectra.

Table 2. Metals extraction by 60 vol\% TBP-20 vol\% P507 at different concentrations of $\mathrm{MgCl}_{2}$.

\begin{tabular}{cccc}
\hline $\mathrm{MgCl}_{2}$ concentration/ & \multicolumn{3}{c}{ Metals extraction/\% } \\
\cline { 2 - 4 }$(\mathrm{M})$ & $\mathrm{Li}^{+}$ & $\mathrm{Fe}^{3+}$ & $\mathrm{Mg}^{2+}$ \\
\hline 0.0 & 0.27 & 78.61 & 0 \\
1.0 & 1.30 & 90.96 & 0.04 \\
\hline
\end{tabular}




\begin{tabular}{llll}
\hline 2.0 & 10.31 & 95.45 & 0.09 \\
3.0 & 37.46 & 96.34 & 0.49 \\
4.0 & 57.34 & 98.96 & 1.87 \\
\hline
\end{tabular}

In summary of the above studies and discussions, the extraction and stripping of $\mathrm{Li}^{+}$and $\mathrm{Fe}^{3+}$ by the new TBP/FeCl$/ 3 / \mathrm{P} 507$ system is as follows: (1) during the lithium extraction, $\mathrm{Li}^{+}$and $\mathrm{Fe}^{3+}$ are co-extracted in the form of $\mathrm{Li} \cdot 2 \mathrm{TBP} \cdot \mathrm{FeCl}_{4}$ at high $\mathrm{Cl}^{-}$concentration; (2) P507 dose not or only slightly involved in the extraction; (3) in the stripping by water, $\mathrm{Fe}^{3+}$ is re-extracted in the form of $\mathrm{FeCl}_{2} \mathrm{~L} \cdot(\mathrm{HL}) \cdot 2 \mathrm{TBP}$ due to the the lack of $\mathrm{Cl}^{-}$, and $\mathrm{Fe}^{3+}$ is maintained in the organic phase with negligible loss into the strip liquor. As a results, after stripping, the organic is readily reusable for next extraction cycle without regeneration because non acid was used for stripping. The extraction and stripping is an equilibrium between the two species of $\mathrm{Li} \cdot 2 \mathrm{TBP} \cdot \mathrm{FeCl}_{4}$ and $\mathrm{FeCl}_{2} \mathrm{~L} \cdot(\mathrm{HL}) \cdot 2 \mathrm{TBP}$, which is controlled by the concentration of $\mathrm{MgCl}_{2}$. The reaction equilibrium is expressed in Eq. (18) and demonstrated in Figure 9 respectively.

$$
\mathrm{LiFeCl}_{4} \cdot 2 \mathrm{TBP} \mathrm{(org)}+(\mathrm{HL})_{2(\text { org })} \rightleftarrows \mathrm{FeCl}_{2} \mathrm{~L} \cdot(\mathrm{HL}) \cdot 2 \mathrm{TBP}_{(\text {org })}+\mathrm{Li}_{(a q)}^{+}+\mathrm{H}_{(a q)}^{+}+2 \mathrm{Cl}_{(a q)}^{-}
$$

Extraction from brine

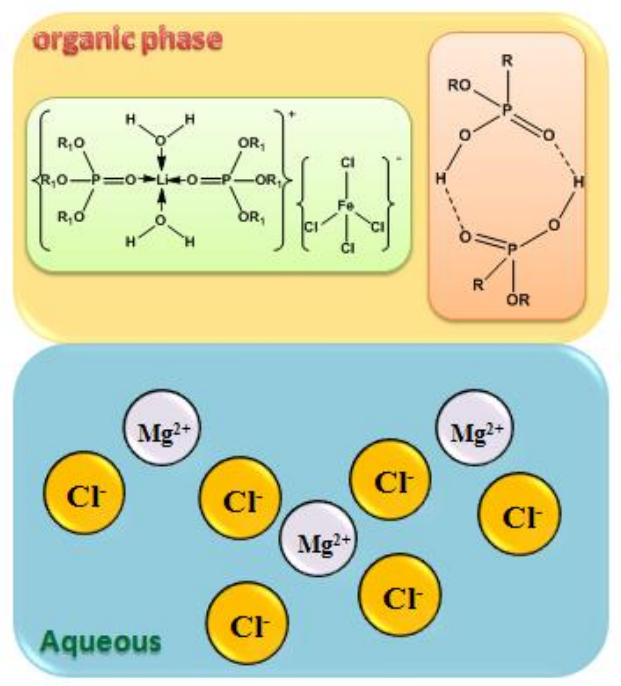

Stripping by water

(Li+)

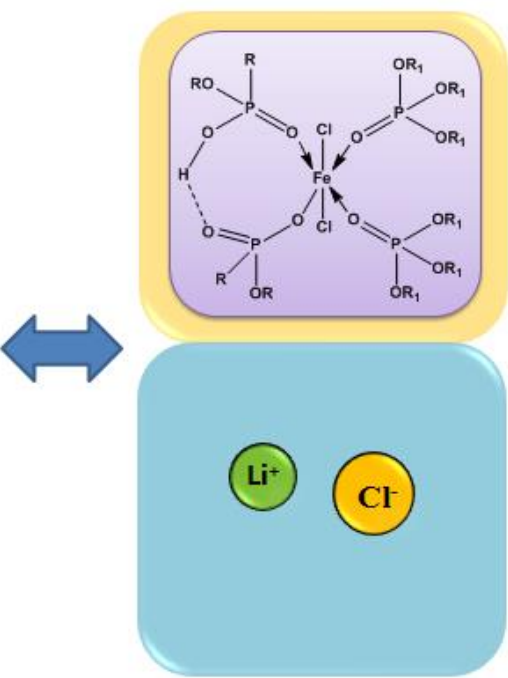


Figure 9. The mechanism of lithium extraction and stripping by the $\mathrm{TBP} / \mathrm{FeCl}_{3} / \mathrm{P} 507$ system.

\section{CONCLUSIONS}

A novel ternary synergistic solvent extraction system of $\mathrm{TBP} / \mathrm{FeCl}_{3} / \mathrm{P} 507$ that combines selectively lithium extraction and easy stripping by regulation of $\mathrm{Fe}^{3+}$ coordination was developed and investigated. 60 vol\% TBP and 20 vol\% P507 diluted in kerosene was used for lithium extraction from a synthetic brine solution of $0.1 \mathrm{M} \mathrm{LiCl}, 4.0 \mathrm{M} \mathrm{MgCl}_{2}$ and $0.13 \mathrm{M} \mathrm{FeCl}_{3}$ $\left(\mathrm{FeCl}_{3}\right.$ is one of the synergistic extraction agents). The loaded organic phase was scrubbed with water at the $\mathrm{O} / \mathrm{A}$ ratio of 20 to largely remove $\mathrm{MgCl}_{2}$, and then stripped with water at the $\mathrm{O} / \mathrm{A}$ ratio of 30 , where $85 \% \mathrm{Li}^{+}$was stripped and the loss of $\mathrm{Fe}^{3+}$ was negligible. The efficient stripping of $\mathrm{Li}^{+}$using water is a significant improvement compared to the existing $\mathrm{TBP} / \mathrm{FeCl}_{3}$ system which requires high $\mathrm{HCl}$ concentration for $\mathrm{Li}^{+}$stripping. Slope analysis and spectroscopic studies show that: $\mathrm{Li}^{+}$and $\mathrm{Fe}^{3+}$ is extracted from the brine solution in the form of $\mathrm{Li} \cdot 2 \mathrm{TBP} \cdot \mathrm{FeCl}_{4}$; $\mathrm{Fe}^{3+}$ is extracted in the form of $\mathrm{FeCl}_{2} \mathrm{~L} \cdot(\mathrm{HL}) \cdot 2 \mathrm{TBP}$ (HL donates P507) when the loaded organic phase is stripped by water. The conversion of the two extracted complexes is controlled by the concentration of $\mathrm{MgCl}_{2}$. This novel ternary solvent extraction system of $\mathrm{TBP} / \mathrm{FeCl}_{3} / \mathrm{P} 507$ considerably enhances $\mathrm{Li}^{+}$stripping while largely maintains $\mathrm{Li}^{+}$extraction efficiency and does not require regeneration of extractants, therefore it is a more sustainable system for $\mathrm{Li}^{+}$extraction from Mg-containing brines and has potential for industrialization. 


\section{AUTHOR INFORMATION}

\section{Corresponding Author}

*Zhaowu Zhu. E-mail: zhwzhu@ipe.ac.cn.

*Tao Qi. E-mail: tqi@ipe.ac.cn.

\section{Notes}

The authors declare no competing financial interest.

\section{ACKNOWLEDGMENTS}

This work was supported by the National Key R\&D Program of China (2018YFC1900500), the

Key Research Program of Frontier Sciences of Chinese Academy of Sciences (Grant No.QYZDJ-SSW-JSC021), the National Natural Science Foundation of China (51774260, 51804289，51904286，21908231) and the CAS Interdisciplinary Innovation Team. 


\section{REFERENCES}

(1) U.S. Geological Survey. Mineral commodity summaries 2018: U.S. Geological Survey. 2018, 200p, https://doi.org/10.3133/70194932.

(2) Statista. Total global consumption of lithium from 2008 to 2016. Accessed on 27 November 2018. www.statista.com/statistics/451999/global-total-consumption-of-lithium/.

(3) Speirs, J.; Contestabile, M. The Future of Lithium Availability for Electric Vehicle Batteries. Renewable \& Sustainable Energy Reviews 2014, 35, 183-193.

(4) Miedema, J. H.; Moll, H. C. Lithium availability in the EU27 for battery-driven vehicles: The impact of recycling and substitution on the confrontation between supply and demand until 2050. Resources Policy 2013, 38, 204-211.

(5) Kesler, S. E.; Gruber, P. W.; Medina, P. A.; Keoleian, G. A.; Everson, M. P.; Wallington, T. J. Global lithium resources: Relative importance of pegmatite, brine and other deposits. Ore Geology Reviews 2012, 48, 55-69.

(6) Choubey, P.; Kim, M.; Srivastava, R.; Lee, J.; Lee, J. Advance review on the exploitation of the prominent energy-storage element: Lithium. Part I: From mineral and brine resources. Miner. Eng. 2016, 89, 119-137.

(7) Cabeza, L. F.; Gutierrez, A.; Barreneche, C.; Ushak, S.; Fernández, A. G.; Inés Fernádez, A.; Grágeda, M. Lithium in thermal energy storage: A state-of-the-art review(Article). Renewable and Sustainable Energy Reviews 2015, 42, 1106-1112.

(8) Zhou, Z.; Wei, Q.; Liang, S.; Tan, Y.; Fei, W. Recovery of lithium using tributyl phosphate in methyl isobutyl ketone and $\mathrm{FeCl}_{3}$. Industrial \& Engineering Chemistry Research 2012, 51, 12926-12932.

(9) Nelli, J. R.; Arthur, T. E.; Gastonia, J. Recovery of Lithium from Bitterns. 1970, US patent. No. US3537813DA.

(10) Huang, S.; Cui, R.; Zhang, S.; Zhou, B. Extraction of lithium from brines of the Da Qaidam salt lake using tributyl phosphate. Journal of Salt Lake Research 1980, 1, 14-23.

(11) Zhu, S.; Pu, X.; Gou, Z. Extraction of lithium brines using neutral phosphorus extractants. Journal of Tsinghua University (Science and Technology) 2000, 40, 47-50.

(12) Yang, L.; Wu, S.; Liu, X.; He, J.; Chen, W. Lithium and magnesium separation from salt lake brine by tributyl phosphate under action of co-extraction reagent $\mathrm{ClO}_{4}^{-}$. Chemical Journal Chinese Universities 2013, 34, 55-60.

(13) Ji, L.; Hu, Y.; Li, L.; Shi, D.; Li, J.; Nie, F.; Song, F.; Zeng, Z.; Sun, W.; Liu, Z. Lithium extraction with a synergistic system of dioctyl phthalate and tributyl phosphate in kerosene and $\mathrm{FeCl}_{3}$. Hydrometallurgy 2016, 162, 71-78.

(14) Zhou, Z.; Qin, W.; Chu, Y.; Fei, W. Elucidation of the structures of tributyl phosphate/Li complexes in the presence of $\mathrm{FeCl}_{3}$ via UV-visible, Raman and IR spectroscopy and the method of continuous variation. Chem. Eng. Sci. 2013, 101, 577-585.

(15) Zhang, Y.; Li, L.; Li, J.; Ji, L.; Xu, Q.; Chen, G. Study on mechanism of extraction of lithium from salt lake brine by tributylphosphate. Inorganic Chemicals Industry 2012, 44, 12-24.

(16) Jia, X.; Li, L.; Zeng, Z.; Liu, Z.; Zhang, Y. Extracting lithium from salt lake brines by TBP extraction system. Inorganic Chemicals Industry 2011, 43, 29-32.

(17) Su, H.; Li, Z.; Zhu, Z.; Wang, L.; Qi, T. Extraction relationship of $\mathrm{Li}^{+}$and $\mathrm{H}^{+}$using tributyl phosphate in the presence of Fe(III). Sep. Sci. Technol. 2019, 1-9.

(18) Lum, K. H.; Stevens, G. W.; Kentish, S. E. The modelling of water and hydrochloric acid extraction by tri-n-butyl phosphate. Chem. Eng. Sci. 2012, 84, 21-30.

(19) Shi, C.; Jia, Y.; Jing, Y. Lithium and magnesium separation from salt lake brine by ionic liquids containing 
tributyl phosphate. CIESC Journal 2015, 66, 253-259.

(20) Shi, C.; Jing, Y.; Xiao, J.; Qiu, F.; Jia, Y. Application of ionic liquids for extraction of lithium from salt lake brine. CIESC Journal 2015, 66, 265-271.

(21) Shi, C.; Yan, J.; Jia, Y. Solvent extraction of lithium ions by tri-n-butyl phosphate using a room temperature ionic liquid. J. Mol. Liq. 2016, 215, 640-646.

(22) Wang, Y.; Liu, H.; Fan, J.; Liu, X.; Hu, Y.; Hu, Y.; Zhou, Z.; Ren, Z. Recovery of lithium ions from salt lake brine with a high magnesium/lithium ratio using heteropolyacid ionic liquid. ACS Sustainable Chemistry \& Engineering 2019, 7, 3062-3072.

(23) Zhang, Y.; Jianning, L. I.; Huang, X.; Wang, C.; Zhu, Z.; Zhang, G. Synergistic extraction of rare earths by mixture of HDEHP and HEH/EHP in sulfuric acid medium. Journal of Rare Earths 2008, 26, 688-692.

(24) Biswas, R. K.; Begum, D. A. Solvent extraction of $\mathrm{Fe}^{3+}$ from chloride solution by D2EHPA in kerosene. Hydrometallurgy 1998, 50, 153-168.

(25) Jin, Y.; Ma, Y.; Weng, Y.; Jia, X.; Li, J. Solvent extraction of Fe ${ }^{3+}$ from the hydrochloric acid route phosphoric acid by D2EHPA in kerosene. Journal of Industrial \& Engineering Chemistry 2014, 20, 3446-3452.

(26) Jayachandran, J.; Dhadke, P. M. Liquid-liquid extraction separation of iron (III) with 2-ethyl hexyl phosphonic acid mono 2-ethyl hexyl ester. Talanta 1997, 44, 1285.

(27) Friedman, H. L. The visible and ultraviolet absorption spectrum of the tetrachloroferrate(III) ion in various media. J. Am. Chem. Soc. 1952, 74, 5-10.

(28) Metzler, D. E.; Myers, R. J. The distribution of ferric iron between hydrochloric acid and isopropyl ether solutions. III. Spectral, isopiestic and magnetic susceptibility studies. J. Am. Chem. Soc. 1950, 72, 3776-3780.

(29) Nachtrieb, N. H.; Conway, J. G. The extraction of ferric chloride by isopropyl ether. I. J. Am. Chem. Soc. 1948, $70,3547-3552$.

(30) Schauble, E. A.; Rossman, G. R.; Jr, H. P. T. Theoretical estimates of equilibrium Fe-isotope fractionations from vibrational spectroscopy. Geochim. Cosmochim. Acta 2001, 65, 2487-2497.

(31) Sitze, M. S.; Schreiter, E. R.; Patterson, E. V.; Freeman, R. G. Ionic liquids based on $\mathrm{FeCl}_{3}$ and $\mathrm{FeCl}_{2}$. Raman scattering and ab initio calculations. Inorg. Chem. 2001, 40, 2298-2304.

(32) Zhang, P.; Guo, Q.; Wei, G.; Meng, L.; Han, L.; Qu, J.; Qi, T. Leaching metals from saprolitic laterite ore using a ferric chloride solution. Journal of Cleaner Production 2016, 112, 3531-3539.

(33) Avery, J. S.; Burbridge, C. D.; Goodgame, D. M. L. Raman spectra of tetrahalo-anions of Fe" $\mathrm{Mn}^{\prime \prime}, \mathrm{Fe}^{\prime \prime}, \mathrm{Cu}^{\prime \prime}$ and Zn". Spectrochimica Acta. Part A: Molecular Spectroscopy 1968, 24, 1721-1726. 
TOC/ABSTRACT GRAPHIC

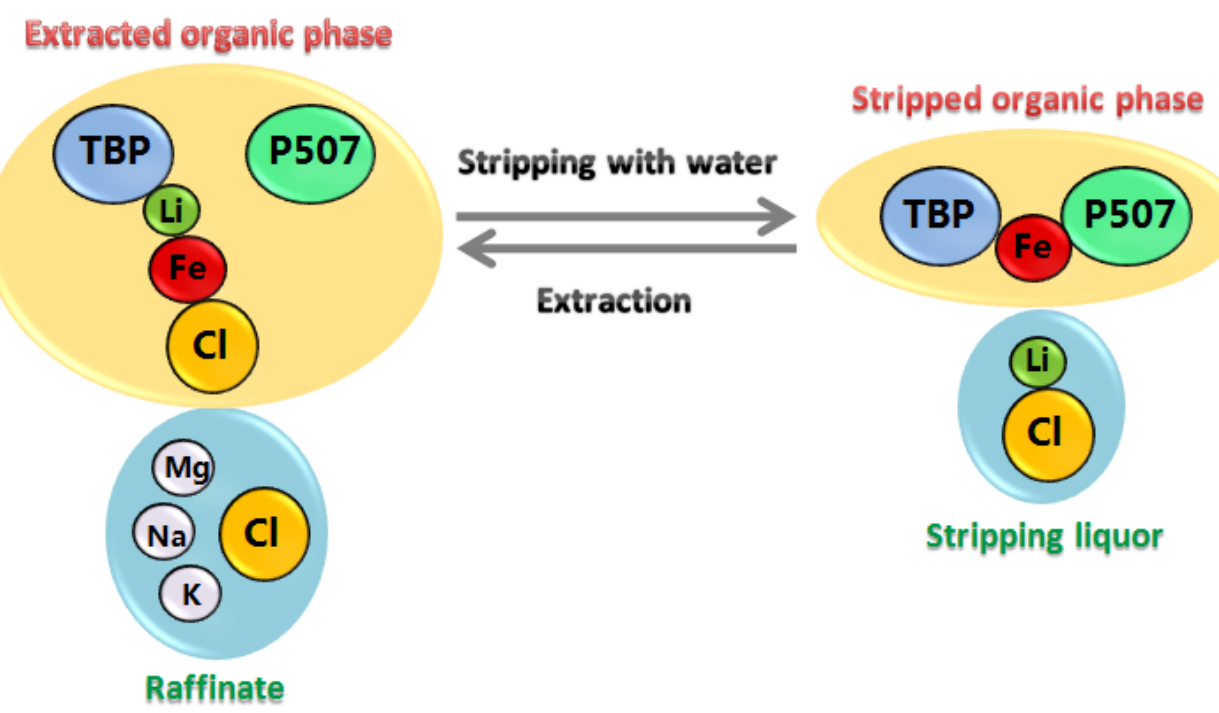

SYNOPSIS

The ternary solvent extraction system $\mathrm{TBP} / \mathrm{FeCl}_{3} / \mathrm{P} 507$ enables efficient and sustainable lithium stripping using water while maintaining selective lithium extraction capacity. 